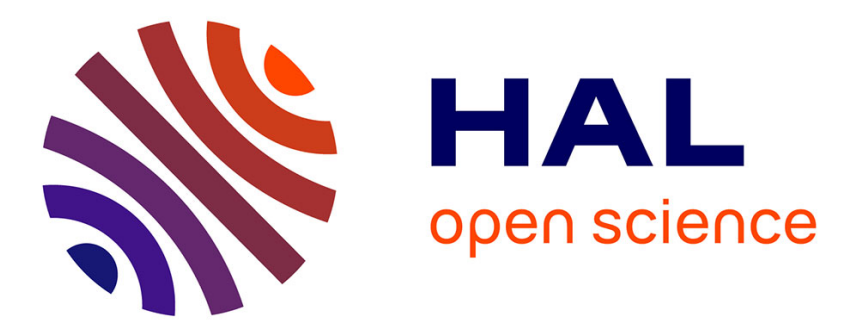

\title{
An Adaptive Sliding Mode Control based Maximum Power Point Tracking method for a PV stand-alone System
}

Ameni Kchaou, Assil Ayadi, Aziz Naamane, Nk M’Sirdi, Yassine Koubaa

\section{- To cite this version:}

Ameni Kchaou, Assil Ayadi, Aziz Naamane, Nk M'Sirdi, Yassine Koubaa. An Adaptive Sliding Mode Control based Maximum Power Point Tracking method for a PV stand-alone System. 6th International Conference on Systems and Control (ICSC'17), May 2017, Batna, Algeria. 10.1109/ICoSC.2017.7958702 . hal-01779883

\section{HAL Id: hal-01779883 \\ https://hal.science/hal-01779883}

Submitted on 27 Apr 2018

HAL is a multi-disciplinary open access archive for the deposit and dissemination of scientific research documents, whether they are published or not. The documents may come from teaching and research institutions in France or abroad, or from public or private research centers.
L'archive ouverte pluridisciplinaire HAL, est destinée au dépôt et à la diffusion de documents scientifiques de niveau recherche, publiés ou non, émanant des établissements d'enseignement et de recherche français ou étrangers, des laboratoires publics ou privés. 


\title{
An Adaptive Sliding Mode Control based Maximum Power Point Tracking method for a PV stand-alone System
}

\author{
Ameni KCHAOU ${ }^{1}$, Assil AYADI ${ }^{1}$, Aziz NAAMANE ${ }^{2}$, Nacer $^{\prime}$ SIRDI $^{2}$ and Yassine KOUBAA ${ }^{1}$
}

\begin{abstract}
This paper presents a photovoltaic (PV) system with an adaptive sliding mode control based maximum power point tracking (MPPT) algorithm. The goal of this work is to maximize power extraction from the photovoltaic generator. This aim is achieved by using an adaptive sliding mode controller (ASMC) that drives a boost converter connected between the PV generator and the load. The robustness and stability of the proposed controller are investigated against weather changes. Simulation results with real data, under MATLABSIMULINK, are given to demonstrate the effectiveness of the proposed approach.
\end{abstract}

Index Terms-PV system, adaptive sliding mode control, MPPT, boost converter

\begin{tabular}{ll} 
& \multicolumn{2}{c}{ NOMENCLATURE } \\
$V_{p v}$ & PV array voltage. \\
$I_{p v}$ & PV array current. \\
$I_{p h}$ & light-generated current. \\
$I_{d}$ & $P V$ saturation current. \\
$I_{r r}$ & saturation current at $T_{r}$. \\
$I_{s c r}$ & short-circuit current at reference condition. \\
$T$ & cell temperature $(\mathrm{K})$. \\
$T_{r}$ & reference temperature. \\
$G$ & solar irradiance (W/m $\left.{ }^{2}\right)$ \\
$G_{n}$ & reference irradiation. \\
$k_{i}$ & short-circuit temperature coefficient. \\
$k_{b}$ & Boltzmann's constant. \\
$q$ & charge of an electron. \\
$A$ & ideality factor. \\
$V_{s}$ & the voltage of the capacitance $C_{s}$. \\
$I_{L}$ & the current on the inductance L. \\
$R_{c}$ & the internal resistance on the capacitance $C_{e}$. \\
$V_{D}$ & the forward voltage of the power diode. \\
$R$ & load resistance. \\
$U$ & duty ratio of the PWM control input signal.
\end{tabular}

\section{INTRODUCTION}

Nowadays, photovoltaic energy sources for power production are getting more and more interesting taking advantage of its availability everywhere and its environmental quality. Photovoltaic energy is more useful in remote sites such as deserts and rural zones where the difficulties to transport

*This work was supported by the Ministry of Higher Education and Scientific Research of Tunisia.

${ }^{1}$ Ameni KCHAOU, Assil AYADI and Yassine KOUBAA are with (lab-STA), National Engineering School of Sfax (ENIS), Tunisia amenikchaoulyahoo.fr, ayadiassildyahoo.fr and yassine.koubaa@enis.rnu.tn

${ }^{2}$ Aziz NAAMANE and Nacer M'SIRDI are with Aix Marseille Université, CNRS, ENSAM, Université de Toulon, LSIS UMR 7296, France aziz.naamanedlsis.org and nacer.msirdielsis.org fuel and the lack of energy lines results in making the use of conventional resources impractical.

The efficiency of a PV system is highly dependent on weather conditions. That's why, extracting the maximum power from the photovoltaic system becomes a challenge. For these reasons, the design of Maximum power point tracking (MPPT) controller is essential in the device operation for successful PV applications.

Over the years, several MPPT algorithms have been developed and widely adapted to search the maximum power point [10] such as Perturb and Observe (P\&O) algorithm [9], the Incremental Conductance (IC) algorithm [3]. There are other approaches based on the artificial intelligence method such as the fuzzy logic [5] and neural network methods [1]. Due to the rapid change of weather conditions, a robust controller seems to be very required to guarantee the tracking of optimal position with high accuracy.

The Sliding Mode Control (SMC) has recently attracted attention from researchers thanks to its advantages [8] which are its ease of implementation, robustness and great performance in different fields. Yet, its main drawback is chattering phenomena caused by the high frequency switching control. To get rid of this obstacle, authors in [4] propose an Adaptive Sliding Mode Control (ASMC). The gain obtained using the adaptive algorithm is not over estimated, so it reduces the oscillations and the chattering.

The main interest of this work is the use of ASMC in the PV system by maximizing the power generated from the PV panels. The proposed control methodology is built into two steps. The first step consists of determining $V_{r e f}$ which represents the maximum power voltage. The second is to perform the system tracking based on the SMC for a boost converter and according to the reference voltage value. The controller uses the error between the measured voltage of the PV module and the voltage generated by the voltage reference to adjust continuously the duty cycle of the DCDC converter so that the error is removed.

The paper is organized as follows: a brief description of the photovoltaic power generation system is presented in Section 2. Section 3 is dedicated to the explanation of the proposed controller. Simulation results are carried out in Section 4. Finally, some conclusions are made up in Section 5.

\section{ELECTRICAL CHARACTERISTICS OF PHOTOVOLTAIC POWER GENERATION SYSTEM}

Generally, a photovoltaic generation system, shown in Fig. 1, contains the following main components: 
1) Photovoltaic generator which converts solar energy into electric energy,

2) DC-DC converter exploiting the generated voltage by the PVG to feed the load voltage,

3) Digital controller that drives the converter commutations according to the MPPT capability,

4) Load.

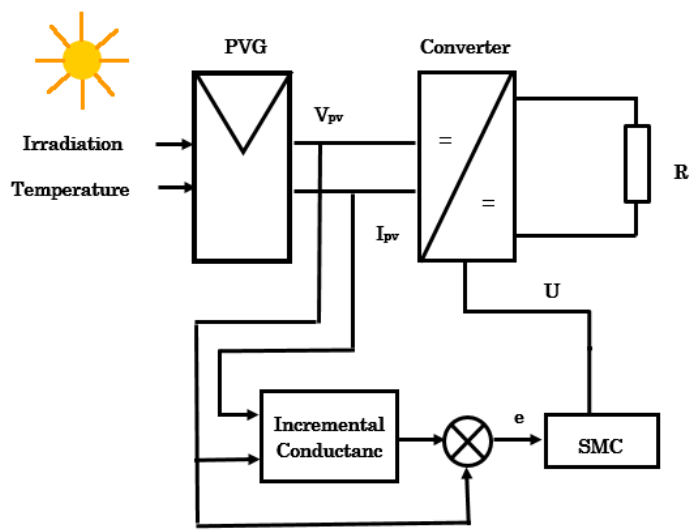

Fig. 1. Synoptic diagram of the photovoltaic system

\section{A. PV generator model}

In literature, it exists several mathematical models [12] that describe the operation and behavior of the photovoltaic generator. In this paper, we use the one diode model.

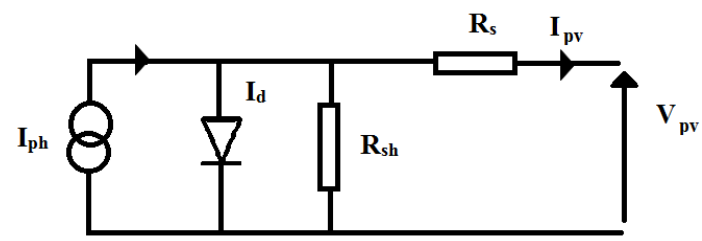

Fig. 2. Simplified equivalent circuit of PV array

Its equivalent circuit, shown in Fig. 2, consists of a light generator source $I_{p h}$, a diode with a reverse saturation current $I_{d}$, a resistance $R_{s h}$ in parallel expressing a leakage current and a serial resistance $R_{S}$ describing an internal resistance to the current flow.

The main equation of the output current of an array is [11]:

$$
I_{p v}=I_{p h}-I_{d}\left[\exp \left(\frac{q V_{p v}}{k_{b} T A}\right)-1\right]-\frac{V_{p v}+R_{p} I_{p v}}{k_{b} T A}
$$

The photo-current expression is given by

$$
I_{p h}=\left(\frac{G}{G_{n}}\right)\left[I_{s c r}+k_{i}\left(T-T_{r}\right)\right]
$$

The saturation current is expressed as

$$
I_{d}=I_{r r}\left[\frac{T}{T_{r}}\right]^{3} \exp \left[\frac{q}{k_{b} T A}\left(\frac{1}{T_{r}}-\frac{1}{T}\right)\right]
$$

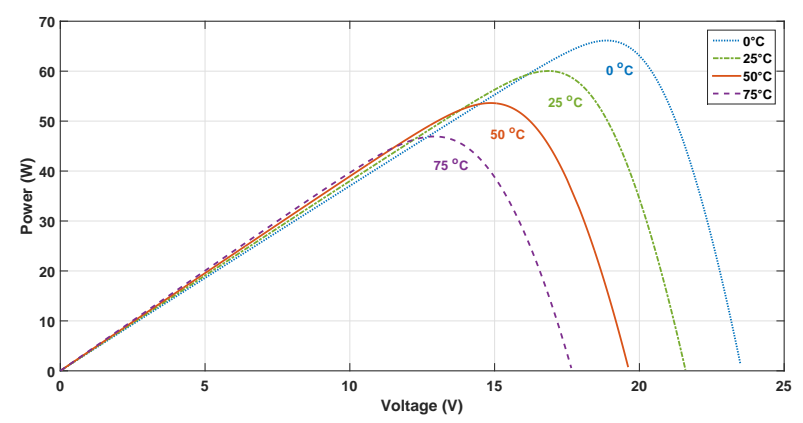

(a) under different temperature values and fixed irradiation $=1000 \mathrm{~W} / \mathrm{m}^{2}$

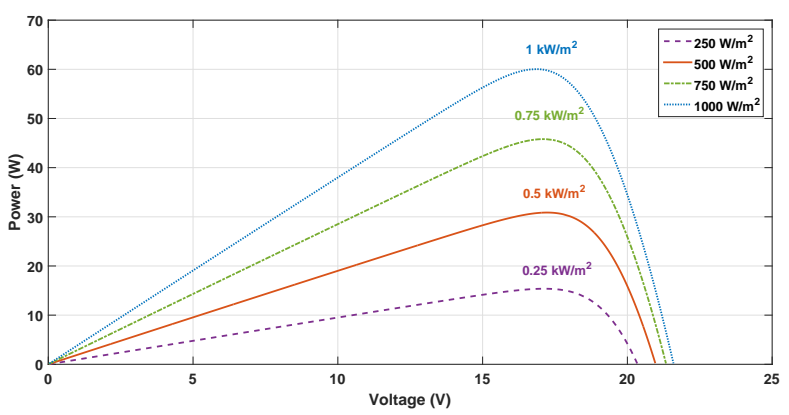

(b) under different irradiation values and fixed temperature $=25^{\circ} \mathrm{C}$

Fig. 3. Power-Voltage characteristics

In fact, $R_{s}$ is taken very large and $R_{s h}$ is taken very small. The PV current becomes

$$
I_{p v}=I_{p h}-I_{d}\left[\exp \left(\frac{q V_{p v}}{k_{b} T A}\right)-1\right]
$$

The Power-Voltage characteristic of the PV panel is plotted in Fig. 3. Considering the first case when only temperature is changing as shown in Fig. 3(a), the photovoltaic power increases whenever the temperature is decreasing. However, for different irradiation levels, Fig. 3(b) shows that the photovoltaic power increases with high value of irradiation.

\section{B. DC-DC converter}

Photovoltaic system needs a boost type converter. It uses an MPPT controller to maintain the maximum output power. The circuit diagram of the converter and the load in shown Fig. 4.

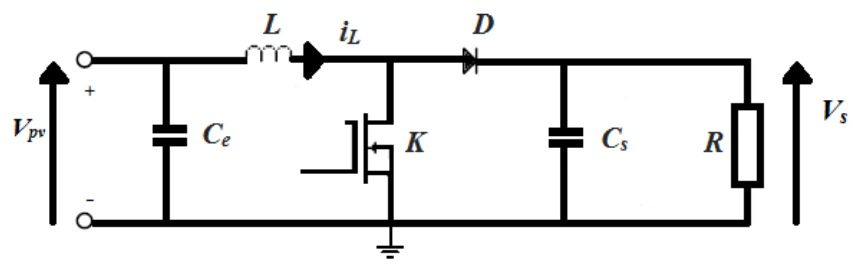

Fig. 4. Simplified equivalent circuit of PV array

The converter [6] is assumed to operate in a continuous conduction mode with two states based on the switch status. 
The dynamics of the boost converter are written as

$$
\left\{\begin{aligned}
\frac{d V_{p v}}{d t} & =\frac{1}{C_{e}}\left(I_{p v}-I_{L}\right) \\
\frac{d I_{L}}{d t} & =\frac{1}{L} V_{p v}-\frac{R_{c}(1-U)}{L\left(1+\frac{R_{c}}{R}\right)} I_{L}-\frac{1-U}{L} V_{D} \\
& +\frac{1-U}{L}\left(\frac{R_{c}}{R+R_{c}}-1\right) V_{s} \\
\frac{d V_{s}}{d t} & =\frac{1-U}{C_{S}\left(1+\frac{R_{c}}{R}\right)} I_{L}-\frac{1}{C_{S}\left(R+R_{c}\right)} V_{s}
\end{aligned}\right.
$$

Let $x_{1}(\mathrm{t})=V_{p v}(\mathrm{t}), x_{2}(\mathrm{t})=I_{L}(\mathrm{t}), x_{3}(\mathrm{t})=V_{s}(\mathrm{t}), x_{1 d}(\mathrm{t})=V_{r e f}(\mathrm{t})$. The system dynamics (5) can be rewritten as

$$
\left\{\begin{array}{l}
\dot{x_{1}}=\frac{1}{C_{e}}\left(I_{p v}-x_{2}\right) \\
\dot{x_{2}}=f_{1}(x)+g_{1}(x) U(t) \\
\dot{x_{3}}=f_{2}(x)+g_{2}(x) U(t)
\end{array}\right.
$$

where $\mathrm{x}=\left[\begin{array}{lll}x_{1} & x_{2} & x_{3}\end{array}\right]^{T}$

$$
\left\{\begin{array}{l}
f_{1}(x)=\frac{x_{1}}{L}-\frac{R_{c}}{L\left(1+\frac{R_{c}}{R}\right)} x_{2}+\frac{1}{L}\left(\frac{R_{c}}{R+R_{c}}-1\right) x_{3}-\frac{1}{L} V_{D} \\
g_{1}(x)=-\frac{R_{c}}{L\left(1+\frac{R_{c}}{R}\right)} x_{2}-\frac{1}{L}\left(\frac{R_{c}}{R+R_{c}}-1\right) x_{3}+\frac{1}{L} V_{D} \\
f_{2}(x)=\frac{1}{C_{e}\left(1+\frac{R_{c}}{R}\right)} x_{2}-\frac{1}{C_{e}\left(R+R_{c}\right)} x_{3} \\
g_{2}(x)=-\frac{1}{C_{S}\left(1+\frac{R_{c}}{R}\right)} x_{2}
\end{array}\right.
$$

\section{Controller DESIGN}

The SMC-MPPT algorithm is divided into two steps:

- In the first step: the reference voltage $V_{\text {ref }}$ value, at which the system reaches its maximum power, is determined via the Incremental Conductance algorithm.

- While in the second step: both controllers, Classical Sliding Mode (CSMC) and Adaptive Sliding Mode (ASMC), use the error between the measured voltage of the photovoltaic module and the reference voltage.

These steps ensure that the system is operating at its optimal point.

\section{A. MPP searching: Incremental Conductance method (IC)}

The Incremental Conductance method (IC) is used to search the MPP voltage $V_{r e f}$. The power slope $\frac{d P_{p v}}{d V_{p v}}$ can be expressed as

$$
\frac{d P_{p v}}{d V_{p v}}=I_{p v}+V_{p v} \frac{d I_{p v}}{d V_{p v}}
$$

In the case When the power slope $\frac{d P_{p v}}{d V_{p v}}=0$, i.e., $\frac{d I_{p v}}{d V_{p v}}=-$ $\frac{I_{p v}}{V_{p v}}$, the photovoltaic system is at the maximum power point. Therefore, the update law for $V_{r e f}$ is given by the following rules

$$
\left\{\begin{array}{lll}
V_{r e f}(k)=V_{r e f}(k-1)+\Delta V & , \text { for } & \frac{d I_{p v}}{d V_{p v}}>-\frac{I_{p v}}{V_{p v}} \\
V_{r e f}(k)=V_{r e f}(k-1)-\Delta V & , \text { for } & \frac{d I_{p v}}{d V_{p v}}<-\frac{I_{p v}}{V_{p v}}
\end{array}\right.
$$

where $V_{r e f}(k)$ is the reference maximum power voltage at $k^{\text {th }}$ step and $\Delta V$ is the update parameter. The flowchart of the searching procedure can be concluded as Fig. 5. After iterative adjustment of $V_{r e f}$, the maximum power condition is achieved only when $\frac{d P_{p v}}{d V_{p v}}=0$.

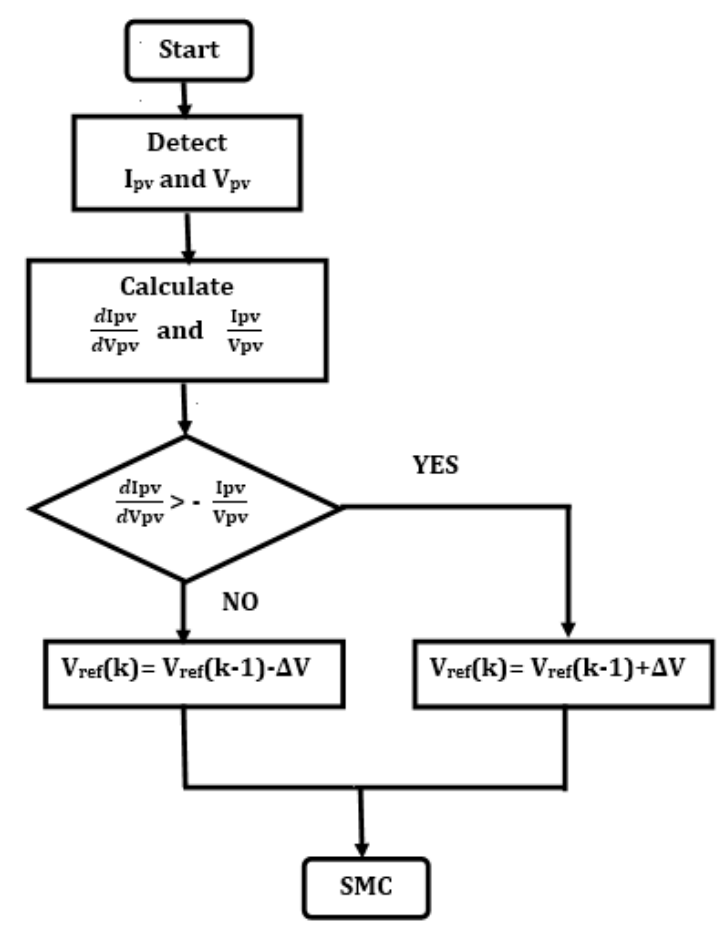

Fig. 5. Flow chart of the maximum power voltage searching algorithm

Thus, the problem is changed to control the PV array voltage $V_{p v}$ to follow the reference maximum power voltage $V_{r e f}$ which is the role of the classical sliding mode and the adaptive sliding mode.

\section{B. Classical Sliding Mode Controller (CSMC)}

To achieve the MPP, the sliding mode controller is introduced. Once $V_{p v}$ always follows $V_{r e f}$, the PV power system will move to the maximum power point along the incremental conductance adjusting. The voltage tracking error and its time derivative are given below:

$$
\left\{\begin{array}{l}
e_{1}(x)=x_{1}-x_{1 d} \\
\dot{e}_{1}(x)=-\frac{1}{C_{e}}\left(-x_{2}+I_{p v}\right)-\dot{x}_{1 d}
\end{array}\right.
$$

Taking $x_{2}$ as a virtual control input, the auxiliary tracking error $e_{2}=x_{2}-x_{2 d}$ with $x_{2 d}=I_{p v}-C_{e} \dot{x}_{1 d}$.

The new dynamics becomes:

$$
\left\{\begin{array}{l}
\dot{e}_{1}(x)=-\frac{e_{2}}{C_{e}} \\
\dot{e}_{2}(x)=f_{1}(x)-\dot{x}_{2 d}+g_{1}(x) U(t)
\end{array}\right.
$$

where $\dot{x}_{2 d}=\dot{I}_{p v}-C_{e} \ddot{x}_{2 d}$.

To gain benefit of a controller, a PID sliding surface is 
designed as in [2]:

$$
S=k_{p} e_{1}+k_{i} \int e_{1}+k_{d} \dot{e}_{1}
$$

where $k_{p}, k_{i}$ and $k_{d}$ are positives constants. These parameters are chosen to engender a Hurwitz polynomial.

Taking the time derivative of (12) yields

$$
\dot{S}=k_{p} \dot{e}_{1}+k_{i} e_{1}+k_{d} \ddot{e}_{1}
$$

Substituting (11) into (13) yields

$$
\begin{aligned}
\dot{S} & =k_{p} \dot{e}_{1}+k_{i} e_{1}-\frac{k_{d}}{C_{e}} \dot{e}_{2} \\
\dot{S} & =k_{p} \dot{e_{1}}+k_{i} e_{1}-\frac{k_{d}}{C_{e}}\left[f_{1}(x)-\dot{x}_{2 d}+g_{1}(x) U(t)\right]
\end{aligned}
$$

The SMC law is designed as

$$
U=U_{e q}+U_{s w}
$$

Forcing $\dot{S}=0$, the equivalent control is obtained as

$$
U_{e q}=\frac{1}{g_{1}(x)}\left[\frac{k_{p}}{k_{d}} C_{e} \dot{e}_{1}+\frac{k_{i}}{k_{d}} C_{e} e_{1}-f_{1}(x)+\dot{x}_{2 d}\right]
$$

The switching term $U_{s w}$ is given by

$$
U_{s w}=\frac{1}{g_{1}(x)} U_{d i s c}
$$

with

$$
U_{\text {disc }}=\eta \operatorname{sign}(S)
$$

where $\eta$ is a positive constant.

The sliding mode control law can be written as

$$
U=\frac{1}{g_{1}(x)}\left[\frac{k_{p}}{k_{d}} C_{e} \dot{e}_{1}+\frac{k_{i}}{k_{d}} C_{e} e_{1}-f_{1}(x)+\dot{x}_{2 d}+\eta \operatorname{sign}(S)\right]
$$

\section{Adaptive Sliding Mode Controller (ASMC)}

1) Control law: The discontinuous term of the classical sliding mode is replaced by an adaptive Proportional Integral term.

$$
U_{s w}=\frac{1}{g_{1}(x)} U_{P I}
$$

The adaptive controller is given in [7] the following expression:

$$
U_{P I}=K_{P} S(t)+K_{I} \int S(t)
$$

where $K_{P}$ and $K_{I}$ are the computed control gains.

The adaptive PI term derived from (21) can be rewritten

$$
U_{P I}=\theta^{T} \psi(S(t))
$$

where $\theta$ and $\psi(S(t))$ are, respectively, the adjustable parameters vector and the regressive vector given by $\theta=\left[\begin{array}{ll}K_{P} & K_{I}\end{array}\right]^{T}$ and $\psi(S(t))=\left[S(t) \int S(t)\right]^{T}$.

Hence, the global control law $\mathrm{U}$ can be expressed as:

$$
U=\frac{1}{g_{1}(x)}\left[\frac{k_{p}}{k_{d}} C_{e} \dot{e}_{1}+\frac{k_{i}}{k_{d}} C_{e} e_{1}-f_{1}(x)+\dot{x}_{2 d}+U_{P I}\right]
$$

The adjustable parameters vector is calculated by the following dynamic equation :

$$
\dot{\hat{\theta}}=\gamma_{k} S \psi(S(t))
$$

where $\gamma_{k}$ is a positive constant.

2) Stability analysis: The approximation error $W_{P I}$ is defined as

$$
W_{P I}=\eta \operatorname{sign}(S)-\theta^{T} \psi(S(t))
$$

We note that $\left\|W_{P I}\right\| \leq W_{P I_{\max }}$.

By replacing the control law $U$ by its expression (14), the time derivative of $\mathrm{S}$ can be rewritten as :

$$
\dot{S}=-\frac{k_{d}}{C_{e}} U_{P I}
$$

The Lyapunov candidate function is chosen as:

$$
V=\frac{1}{2} S^{2}+\frac{1}{2 \delta_{k}} \tilde{\theta}^{T} \tilde{\theta}
$$

where $\tilde{\theta}=\theta-\hat{\theta}$.

The time derivative of the lyapunov function is:

$$
\dot{V}=S \dot{S}+\frac{1}{\delta_{k}} \tilde{\theta}^{T} \dot{\tilde{\theta}}
$$

Replacing the time derivative of the sliding surface given by (26) and adding (25) in the derivative of $\mathrm{V}$, it results :

$$
\begin{aligned}
\dot{V} & =S \frac{k_{d}}{C_{e}}\left[-U_{P I}+W_{P I}-\eta \operatorname{sign}(S)+\theta^{T} \psi(S(t))\right] \\
& +\frac{1}{\delta_{k}} \tilde{\theta}^{T} \dot{\tilde{\theta}} \\
& =S \frac{k_{d}}{C_{e}}\left[-\hat{\theta}^{T} \psi\left(S(t)+W_{P I}-\eta \operatorname{sign}(S)\right.\right. \\
& \left.+\theta^{T} \psi(S(t))\right]+\frac{1}{\delta_{k}} \tilde{\theta}^{T} \dot{\tilde{\theta}} \\
& =S \frac{k_{d}}{C_{e}}\left[\tilde{\theta}^{T} \psi\left(S(t)+W_{P I}-\eta \operatorname{sign}(S)\right]\right. \\
& +\frac{1}{\delta_{k}} \tilde{\theta}^{T} \dot{\tilde{\theta}}
\end{aligned}
$$

Baring in mind that $\dot{\tilde{\theta}}=-\dot{\hat{\theta}}$, (29) can be rewritten as

$$
\begin{aligned}
\dot{V} & =S \frac{k_{d}}{C_{e}}\left[\tilde{\theta}^{T} \psi\left(S(t)+W_{P I}-\eta \operatorname{sign}(S)\right]\right. \\
& -\frac{1}{\delta_{k}} \tilde{\theta}^{T} \dot{\hat{\theta}} \\
& =\tilde{\theta}^{T} \frac{k_{d}}{C_{e}}\left(S \psi\left(S(t)-\frac{1}{\delta_{k}} \dot{\hat{\theta}}\right)\right. \\
& -\eta \frac{k_{d}}{C_{e}} \operatorname{Ssign}(S)+S \frac{k_{d}}{C_{e}} W_{P I}
\end{aligned}
$$

By substituting (24) in (30), we get

$$
\begin{aligned}
\dot{V} & =-\eta \frac{k_{d}}{C_{e}} \operatorname{Ssign}(S)+S \frac{k_{d}}{C_{e}} W_{P I} \\
\dot{V} & \leq-\eta|S| \frac{k_{d}}{C_{e}}+|S| \frac{k_{d}}{C_{e}} W_{P I_{\max }} \\
\dot{V} & \leq|S| \frac{k_{d}}{C_{e}}\left(W_{P I_{\max }}-\eta\right)
\end{aligned}
$$


Finally, we obtain $\dot{V}<0 \forall \eta>W_{P I_{\max }}$

Applying Barbalat's lemma, the sliding surface converges asymptotically to zero in finite time.

\section{Simulation Results}

The PV array contains 36 cells connected in series. The specifications of the PV panel are stated in Table. I. The boost converter operates with $\mathrm{L}=10 \mathrm{mH}$ and $\mathrm{C}=470 \mu \mathrm{F}$. The switching frequency of the converter is set to $f_{s w}=20$ $\mathrm{kHz}$. The frequency of the searching algorithm is also set as $20 \mathrm{kHz}$.

TABLE I

\section{PV SPECIFICATION}

\begin{tabular}{ll}
\hline Parameters & Value \\
\hline Saturation current at $T_{r}\left(I_{r r}\right)$ & $5.981 \times 10^{-8} A$ \\
Short circuit current at reference condition $\left(I_{s c r}\right)$ & $3.81(A)$ \\
Reference Temperature $\left(T_{r}\right)$ & $298(K)$ \\
Ideality Factor $(A)$ & 1.2 \\
Charge of an electron $(q)$ & $1.6 \times 10^{-19}(C)$ \\
Temperature coefficient $\left(k_{i}\right)$ & 0.0024 \\
Boltzman's constant $\left(k_{b}\right)$ & $1.3806 \times 10^{-23}$ \\
Maximum Photovoltaic Power $\left(P_{m p p}\right)$ & $60.27(\mathrm{~W})$ \\
Maximum Photovoltaic Voltage $\left(V_{m p p}\right)$ & $16.85(\mathrm{~V})$ \\
Maximum Photovoltaic current $\left(I_{m p p}\right)$ & $3.57(\mathrm{~A})$ \\
\hline
\end{tabular}

In the following, two scenarios including standards conditions and varying temperature and irradiation are simulated to verify the proposed scheme.

\section{A. Standards conditions: $T=25^{\circ} \mathrm{C}$ and $\mathrm{Ir}=1000 \mathrm{~W} / \mathrm{m}^{2}$}

PV voltage $V_{p v}$ is provided in Fig. 6 along with PV power $P_{p v}$ is shown in Fig. 7.

The system response is shown in Fig. 6(a) with CSMC and ASMC in Fig. 6(b). With ASMC, the PV system shows a fast response and a good tracking performance. In fact, the tracking errors based on MAE (32) and MSE (33) given in Table II, are minimum for ASMC. Furthermore, PV voltage converges to the desired voltage within $0.01 \mathrm{sec}$. However, by using CSMC, the time convergence is about $0.02 \mathrm{sec}$. ASMC also presents less oscillation comparing to CSMC. PV power is also maintained at its optimum after $0.009 \mathrm{sec}$ for ASMC in Fig. 7(b) and $0.015 \mathrm{sec}$ for CSMC in Fig. 7(a).

TABLE II

COMPARATIVE STUdY OF SMC AND ASMC

\begin{tabular}{cccc}
\hline & MAE & MSE & Time of convergence \\
\hline CSMC & 0.3127 & 1.3764 & $0.02 \mathrm{sec}$ \\
ASMC & 0.1771 & 1.1179 & $0.01 \mathrm{sec}$ \\
\hline$M A E$ & $=\frac{1}{T} \int_{0}^{T}|e(t)| d t$ \\
$M S E$ & $=\frac{1}{T} \int_{0}^{T} e^{2}(t) d t$
\end{tabular}

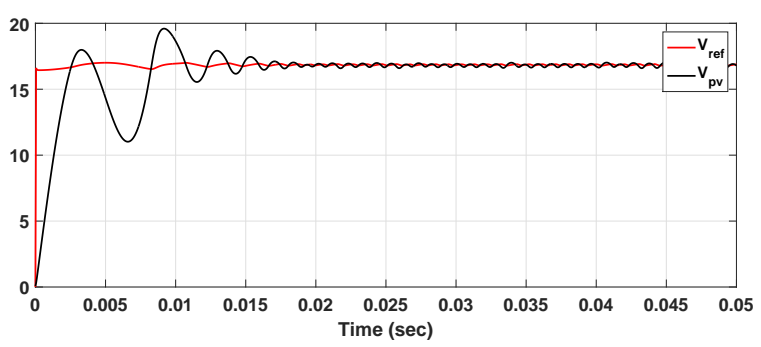

(a) Classical SMC

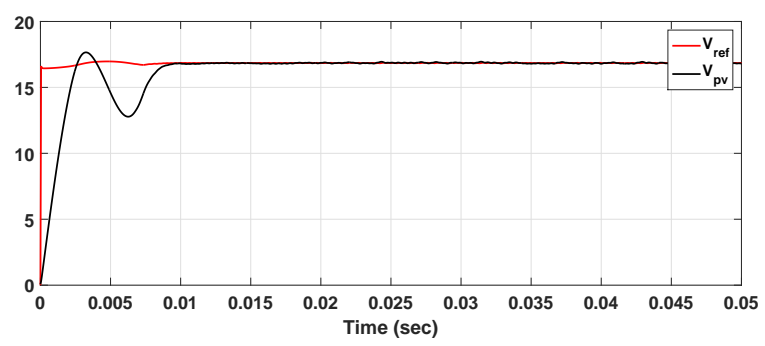

(b) Adaptive SMC

Fig. 6. PV voltage (V)

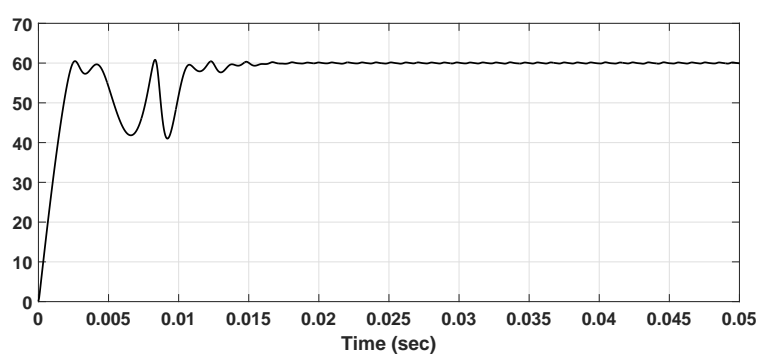

(a) Classical SMC

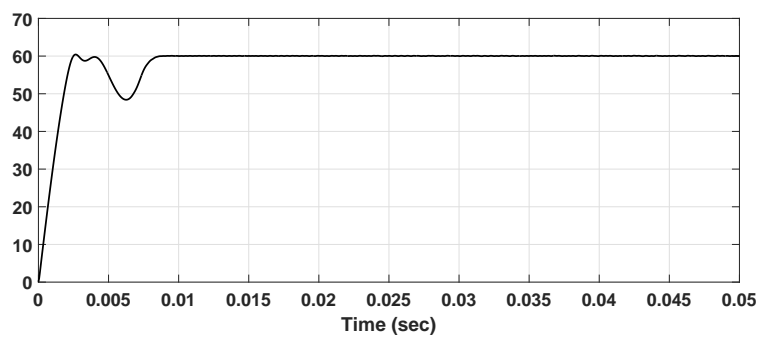

(b) Adaptive SMC

Fig. 7. PV power $P_{p v}(\mathrm{~W})$ 


\section{B. Real data analysis}

In this simulation, we take real data measured for one day (16/11/2016) in the region of Sfax in Tunisia. The data is varied each 3 hours. Irradiation and temperature profiles are given in Fig. 8.

The PV power is given in Fig. 9. Under the simultaneous variation of temperature and irradiation, as it shown in Fig. 9(b), ASMC tracks perfectly the maximum power. However, CSMC tracks the maximum power but with oscillations around it as it given by Fig. 9(a).

\section{CONCLUSIONS}

In this paper, sliding mode controller based MPPT algorithm has been introduced for the maximum power tracking of PV systems. By combining the ASMC controller and the incremental conductance method, the MPP is successfully achieved even considering rapidly changing atmosphere. Via simulations, the better performance has been obtained compared to CSMC. Furthermore, the ASMC-based MPPT control method assures better tracking performance and high robustness.

\section{ACKNOWLEDGMENT}

This work was supported by the Ministry of Higher Education and Scientific Research of Tunisia.

\section{REFERENCES}

[1] A. Chatterjee and A. Keyhani. Neural network estimation of microgrid maximum solar power. IEEE Transactions on Smart Grid, 3(4):18601866, Dec 2012.

[2] Ranjbar A.N. Ghaderi R. et al. Delavari, H. Fractional order control of a coupled tank. Nonlinear Dyn, 2010.

[3] M. A. Elgendy, B. Zahawi, and D. J. Atkinson. Assessment of the incremental conductance maximum power point tracking algorithm. IEEE Transactions on Sustainable Energy, 4(1):108-117, Jan 2013.

[4] H. El Fadil, F. Giri, and Josep M. Guerrero. Adaptive sliding mode control of interleaved parallel boost converter for fuel cell energy generation system. Mathematics and Computers in Simulation, 91:193 - 210, 2013. \{ELECTRIMACS $\} 2011-\{$ PART $\}$ III.

[5] A. El Khateb, N. A. Rahim, J. Selvaraj, and M. N. Uddin. Fuzzy-logiccontroller-based sepic converter for maximum power point tracking. IEEE Transactions on Industry Applications, 50(4):2349-2358, July 2014.

[6] P. T. Krein, J. Bentsman, R. M. Bass, and B. L. Lesieutre. On the use of averaging for the analysis of power electronic systems. IEEE Transactions on Power Electronics, 5(2):182-190, Apr 1990.

[7] S. Larguech, S. Aloui, O. Pags, A. E. Hajjaji, and A. Chaari. Adaptive sliding mode control for a class of nonlinear mimo systems: Application to a turbocharged diesel engine. In 22nd Mediterranean Conference on Control and Automation, pages 1205-1210, June 2014.

[8] Y. Levron and D. Shmilovitz. Maximum power point tracking employing sliding mode control. IEEE Transactions on Circuits and Systems I: Regular Papers, 60(3):724-732, March 2013.

[9] Nacer Kouider M'Sirdi and Bechara Nehme. The vsas approach gives the best mppt for solar energy sources. Renewable Energy and Sustainable Development, 1(1):60 - 71, 2015.

[10] V. Salas, E. Olas, A. Barrado, and A. Lzaro. Review of the maximum power point tracking algorithms for stand-alone photovoltaic systems. Solar Energy Materials and Solar Cells, 90(11):1555 - 1578, 2006.

[11] Gayatri Agnihotri Savita Nema, R.K.Nema. Matlab / simulink based study of photovoltaic cells / modules / array and their experimental verification. INTERNATIONAL JOURNAL OF ENERGY AND ENVIRONMENT, 1,(3,):487-500, 2010.

[12] M. G. Villalva, J. R. Gazoli, and E. R. Filho. Comprehensive approach to modeling and simulation of photovoltaic arrays. IEEE Transactions on Power Electronics, 24(5):1198-1208, May 2009.

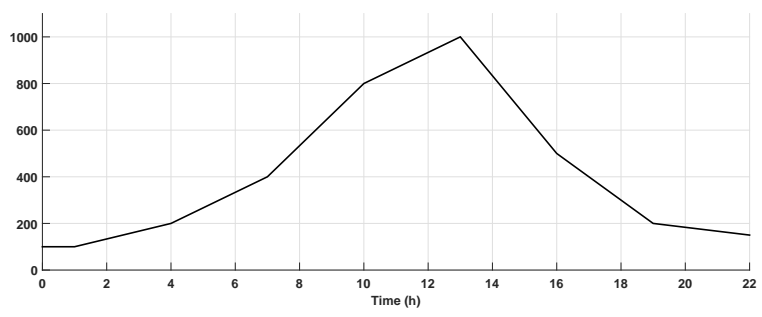

(a) Solar irradiance $\operatorname{Ir}\left(W / m^{2}\right)$

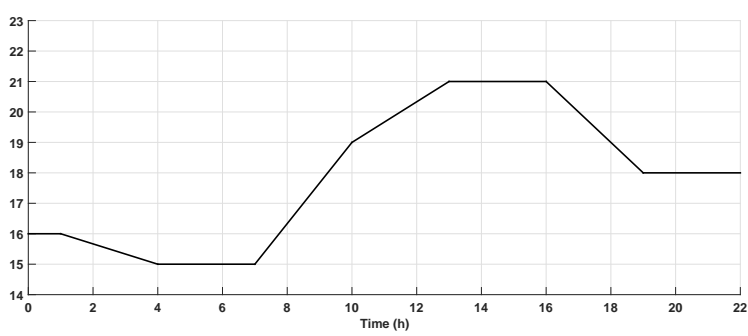

(b) Temperature $\left({ }^{\circ} \mathrm{C}\right)$

Fig. 8. Solar irradiance and temperature taken for one day

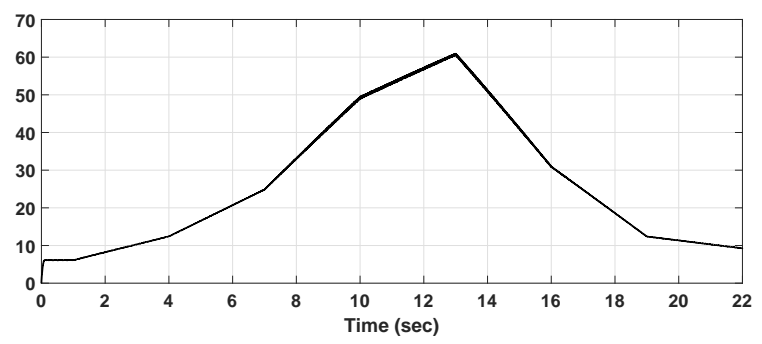

(a) Classical SMC

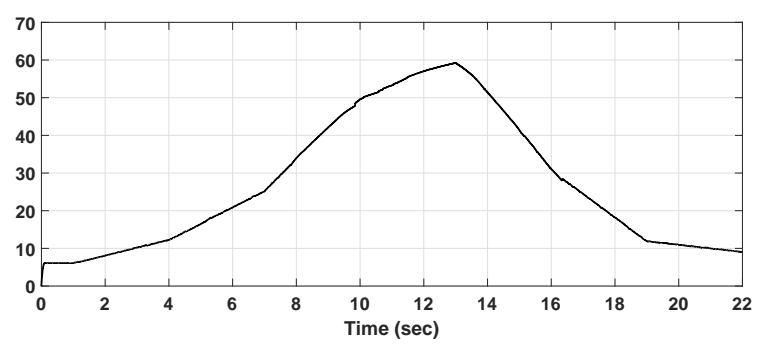

(b) Adaptive SMC

Fig. 9. $\quad$ PV power $P_{p v}(W)$ 